The experience of academic librarians in the public sector with respect to unit determination is not under the jurisdiction of the NLRB, but is rather governed by state law and/or boards. As such it is appropriately the subject of another review and is beyond the intended scope of the essay. Readers are reminded that the scope of bargaining units can also be set by consent such that it is possible that librarians may not be in the unit with faculty by agreement between bargaining agent and employer.

\section{Rearerences}

1. C. W. Post Center of Long Island University 189 NLRB 906 (1971).

2. Fordham University 193 NLRB 139 (1971).

3. Ibid, 140, note 23.

4. For a review of the arguments see Ralph E. Kennedy, "The Educator's Role in Educating the NLRB." Journal of College and
University Law (Summer 1974), p.308-11.

5. Florida Southern College 196 NLRB 889 (1972).

6. Tusculum College 199 NLRB 31 (1972).

7. Catholic University 201 NLRB 145 (1973); New York University 205 NLRB 16 (1973); University of San Francisco 207 NLRB 15 (1973); Point Park College 209 NLRB 152 (1974); Fordham University 214 NLRB 37 (1974); Rensselaer Polytechnic Institute 218 NLRB 220 (1975).

8. Adelphi University 195 NLRB 639 (1972).

9. 205 NLRB 16 ( 1973 ).

10. Ibid.

11. University of Chicago Library 205 NLRB 44 (1973).

12. University of Chicago vs. NLRB (unpublished order \#73-1788, Case 13-CA11447 ).

13. 198 NLRB 121 ( 1972$).$

\title{
NELINET - ACRL/NEC Joint Meeting and Conference
}

\section{Reported by \\ Jacqueline Seuss \\ Acquisitions Librarian \\ Boston College}

Because of a common interest in developing simple cost measures for use in libraries, the membership of NELINET and the membership of the ACRL-New England Chapter met together in a joint meeting and conference chaired by Gai Carpenter, NELINET Executive Committee and director of the Harold F. Johnson Library Center, Hampshire College, at the New England Center for Continuing Education in Durham, New Hampshire, on Friday, November 14, 1975.

In the morning separate business meetings were held by each group. The business meeting of the ACRL-New England Chapter will be reported separately in the February issue of $C \& R L$ News under "News from the Chapters." Reporting to the NELINET membership, Robert F. Miller, the director of NELINET, highlighted recent activities in which NELINET has been engaged, namely, further democratizing the governance system and accessing the impact of the recent OCLC rate increase. Future activities to be given high priority, he stated, were (1) to resolve the future of the Northeast Academic Science Information Center (NASIC), (2) to complete by December the National Agricultural Library project, and (3) to conclude negotiations with OCLC. Also reporting at the NELINET business meeting was Frederick G. Kilgour, director of the Ohio College Library Center. Mr. Kilgour stated that the biggest problem facing OCLC was that of capitalization, explaining that funds for capital expenditure must now be provided by the users rather than the vendors. Using the Ohio experience by way of illustration, he estimated that the recent rate increase amounted to only 13 percent while at the same time usage had increased 18 percent. After briefly summarizing the accomplishments of the OCLC system, he outlined expansion of service in 1976 into the areas of automated check-in, acquisitions, interlibrary loan, and subject retrieval.

Upon completion of the business meetings, the joint conference was opened by an address entitled "Library Cost Analysis: What We Need to Know and Why" by Sherrie S. Bergman, librarian, Wheaton College. Budget justification, Ms. Bergman pointed out, is one of the primary reasons for employing more sophisticated analyses, the traditional approach of circulation figures, for example, often being inadequate and misleading. Almost any library operation can be measured, she said, and the relationship between cost and production can be established. Ms. Bergman suggested that after the librarian has selected the specific areas of study, several basic principles of cost analysis should be remembered: measurement almost always contains error and only a level of precision that is acceptable need be applied; the 
study should be as simple as possible and the results presented by ratios and in graphic form. Finally, the study should meet the test of reasonableness: Can it be compared to similar categories of measurement with institutions of similar size and purpose?

An address by Dr. Donald Vincent, university librarian, University of New Hampshire, concluded the morning's proceedings. Mr. Vincent presented the methods and results of analyzing cataloging costs conducted with and without computer assistance at his library between the years 1971/72 and 1974/75. The study revealed the necessity for constant revision of the number of operations defined, measured, and analyzed. It further revealed that the employment of the NELINET system reduced the ratio between total dollars spent and volumes added, despite substantial increases in salaries. The study, he explained, was only one approach to technical processing cost analysis and that like any set of statistics, it reflected "facts, estimates and opinions."

Three case studies applying analytical techniques to technical services, collection development, and on-line reference searching, held concomitantly, opened the afternoon session of the conference.

\section{Case Study-Technical Services}

Conducting this discussion, Don Vincent further elaborated upon his morning presentation concerning the cost analysis project undertaken by his library. After a brief description of the problems they encountered with the computer programming aspects of the study, Mr. Vincent went on to point out a number of items that must be given careful consideration when setting up a cost analysis study. One item was fringe benefits and how they should be counted in the study. Another, and probably the most important, was staff cooperation. He stressed the need for an effective orientation of the staff to the study. In a final comment Mr. Vincent was careful to note that the cost analysis they conducted was not a cost-benefit analysis as it did not measure the quality of the work performed nor did it allow for special projects, i.e., an unusually large number of Russian materials being cataloged during the course of the analysis.

The discussion was rounded out by a short presentation given by Vaughn Simon, head of cataloging at Dartmouth College. Mr. Simon described the cost analysis study he designed and conducted at Dartmouth, noting its similarities and differences with the study done at the University of New Hampshire.

\section{Case Study-Collection Development}

Peter Oliver, director, Andover-Harvard Theological Library and Linda B. Lewkowicz, coordinator of library services, Boston Theological
Institute, presented a case study illustrating the methods and results of a computer-assisted analysis of the collection of 1973 imprints by members in the consortium of the Boston Theological Institute. The breakdown into separate categories of the BL to BX classification schedule revealed, among other things, a "bibliographic uniqueness" index for each subdivision of the classification range for each library. These figures indicated the number and percentage of titles held by only one library in the consortium. In addition, the study was also constructed to reveal the number and percentage of titles held by one or more other libraries in the consortium. In such a way, it was pointed out, the strengths and weaknesses of the member libraries might be assessed and future collection development policy might be established for both the member libraries individually and the consortium as a whole.

\section{Case Study-On-Line Reference SEARCHING}

During the past two years, NASIC (the Northeast Academic Science Information Center) has assisted thirty-two academic and research institutions in establishing on-line bibliographic searching within their libraries. In preparing for the operation of a search service, NASIC works with the participating institution in four ways: training, administrative consultation, user education, and interface with the service vendors. Since the end user usually pays for the out-of-pocket costs (computer connect time, communications charges and fees for offline printing) at most institutions, the major costs for the library are staff time, terminal acquisition and publicity. On-line searching is an add-on responsibility for the professional academic librarian where time must be allocated for a number of functions: user consultation, strategy development, on-line searching, record keeping and promotional activities. The impact of heavy on-line searching will probably affect interlibrary loan. For the library, the positive aspects have been an improved public relations image, the capability to offer broader and deeper subject bibliographies, and greater knowledge of the printed counterparts. For the medium-sized or smaller academic library, computerized searching has meant increased access to literature sources.

Editor's note: This case study was conducted by Patricia Vaughan, Information Services Librarian, Northeast Academic Science Information Center (NASIC), Wellesley, Mass.

The conference was concluded with an address "Does the New Librarianship Affect Traditional Approaches to Cost Analysis in Li-

\section{Continued on page 6}




\section{Report on the Conference on Retrenchment}

\section{in Higher Education: Implications for Libraries}

\author{
Submitted by \\ Lynn Barber \\ Acquisitions Librarian \\ Skidmore College
}

On November 14, amid rumors of budgetary freezes, fiscal default and the first snow of the season, the Eastern New York Chapter of ACRL held its first conference and official business meeting. The topic for the day's discussions was "Retrenchment in Higher Education: Implications for Libraries," and nearly seventyfive librarians came to the SUNY Albany campus to compare problems and suggestions for solutions.

The meeting commenced with a welcome from the new president of SUNY Albany, Emmett B. Fields. In addressing the group, President Fields emphasized the need for resolving the problems of retrenchment without inhibiting the progress of higher education. He stated that universities must move forward or risk dying. Following Fields, G. Richard Wynn, vice-president and treasurer of Cedar Crest College, Allentown, Pennsylvania, and Millicent D. Abell, associate director of libraries, SUNY Buffalo, addressed the issues of retrenchment as they have affected their respective institutions.

\section{NELINET}

Continued from page 4

braries" by Frederick G. Kilgour. Mr. Kilgour defined the "new librarianship" as that which employs new technology to new objectives. He went on to define the new technology to be a system such as OCLC and the new objective as making more resources available at reduced costs. He predicted that the new librarianship will require librarians to view things from an economic point of view, using techniques of cost analysis, rather than from a budget point of view, requiring an expenditure analysis. $\mathrm{He}$ further predicted that librarians will soon be required to reduce costs in overhead and costs to users, cost to users meaning that the user fails-- a good 50 percent of the time-to obtain the information or material he needs from the library. In conclusion, he stated that the employment of the technology offered by the OCLC system will enable libraries to reduce both overhead costs and costs to users because of both its economy of scale and its economy of time and labor.
G. Richard Wynn spoke as an administrator making budgetary decisions at a small, private college. He cited a number of areas which he saw as primary considerations in dealing with tight financial situations. Among them were the necessity for viewing higher education much like any contractor that must attract users of its services. Wynn saw this as particularly important due to the fact that statistical projections indicate the number of high school seniors going on to college is declining. The pricing factor, particularly the significant differences in the financial bases and requirements of public and private institutions must be dealt with, and particularly in the context of financial aid to students. Productivity as it affects faculty and students must also be considered as institutions attempt to find ways to deal with diminishing working capital. The effects of inflation on libraries must be recognized by administrators with all its implications to library services and purchasing power. In concluding, Wynn emphasized the importance of measuring "quality distress" as libraries find their budgets being cut and the need for developing meaningful quantitative measures for library services.

Millicent "Penny" Abell followed Wynn, speaking as a librarian who must deal with the budgetary decisions of institutional administrators. Abell spoke out strongly on the overwhelming pressure placed on libraries in meeting their broad objectives with diminishing funds. She suggested that librarians must develop a "toughness" to deal with retrenchment and learn to be innovative in finding ways to modify expectations while at the same time fully utilizing all their resources. Abell emphasized that libraries should not hope to only "wait out" the current economic problems, for the situation demands realistic confrontation. "Growth" cannot be used as an excuse for poor management in personnel or service decisions. Abell was optimistic, however, in feeling that the reassessment that libraries must face up to may ultimately lead to better definitions of objectives, new measures of performance, and a rearrangement of priorities to better reflect available resources and talents. In summary, Abell challenged participants to find ways of doing more with existing budgets through a process of reevaluation to identify new areas of both internal and external cooperation. She warned that libraries must not squander the resources they do have, but rather, they must establish a balance of operation incorporating courage, humaneness, and strength. 